\title{
Paradojas en el discurso educativo sobre la discriminación: ¿un trasfondo disciplinar?¹
}

\section{Paradoxes in the educational discourse about discrimination: a disciplinary background?}

\section{DOI: $10.32870 /$ dse.v0i19.544}

\section{Laura Victoria Martínez*}

\begin{abstract}
Resumen
En este trabajo se reconstruyen paradojas en la configuración concreta y situada del principio jurídico de igualdad y no discriminación, y del paradigma de respeto a la diversidad desde el que se suelen abordar los conflictos discriminatorios en la escuela. Desde un abordaje etnográfico que privilegia las categorías sociales y los significados sobre los términos jurídicos como la discriminación, se analiza el plano del trato interpersonal y, como parte de él, las emociones que verbalizan las niñas y los niños. Se parte de considerar aspectos de los discursos de estado sobre la discriminación, como el enfoque jurídico de los actos discriminatorios y su tendencia a clausurarlo en relaciones de trato, y el sesgo actitudinal. Se reconstruyen estos aspectos en prácticas y relaciones cotidianas en una escuela pública de una zona empobrecida del sur de la Ciudad de Buenos Aires, donde la discriminación se vincula sistemáticamente a matrices de sentido individualizantes sobre las y los niños como alumnos/as, y los efectos paradójicos en torno a la regulación de sus verbalizaciones discriminatorias. Se concluye planteando tensiones entre un trasfondo disciplinar del discurso escolar, y las demandas colectivas históricas contra la discriminación.
\end{abstract}

Palabras clave: discriminación - discurso escolar - disciplinar - etnografía.

\begin{abstract}
This paper analyzes paradoxes in the concrete and situated configuration of the legal principle of equality and non-discrimination, as well as the paradigm of respect for diversity through which conflicts about discrimination are addressed at school. With an ethnographic approach that privileges social categories and meanings over legal terms such as discrimination, it analyzes interpersonal relationships and the emotions that children verbalize. It starts by considering aspects of the state discourse on discrimination such as the legal approach to discriminatory acts and their tendency to constrain it to terms of treatment and attitudinal bias. These aspects are reconstructed in everyday practices and relationships in a public school
\end{abstract}

1 Este trabajo presenta resultados parciales de una investigación finalizada, la tesis doctoral de la autora (2017). Dicha investigación ha sido financiada por el Consejo Nacional de Investigaciones Científicas y Técnicas (CONICET).

* Doctora en Antropología, docencia de grado y posgrado y participación en equipos de investigación, Universidad de Buenos Aires, Facultad de Filosofía y Letras-Sección de Antropología Social-Programa de Antropología y Educación y, Universidad Pedagógica Nacional, Departamento de Ciencias Sociales y Educación. Argentina. lauvicmartinez@yahoo.com.ar 
in an impoverished neighborhood of Buenos Aires, where discrimination is systematically linked to individualizing matrices of meaning about children as students, and the paradoxical effects on the regulation of their discriminatory verbalizations. It concludes by reconstructing the tensions between the disciplinary background of educational discourse and the collective and historical demands against discrimination.

Key words: Discrimination - educational discourse - disciplinary - ethnography

\section{Introducción}

En el ámbito argentino, la discriminación es una categoría jurídica y política, y a la vez un término usado en el lenguaje cotidiano. Su temprana entrada en el ámbito local mediante la Ley de Actos Discriminatorios 23.592 de 1988, su nivel de institucionalización con un organismo estatal específico, el Instituto Nacional Contra la Discriminación, la Xenofobia y el Racismo (INADI), pueden explicar su alto despliegue en el discurso cotidiano en comparación con otros términos políticos. En el lenguaje jurídico, la discriminación nombra actos vulneratorios del principio de igualdad y el derecho a la no discriminación (Gutiérrez Rivas, 2014). Si la genealogía de la ley contra la discriminación debe inscribirse necesariamente en un conjunto de normativas y consensos en el marco internacional de los derechos humanos, otro tanto corresponde decir sobre el ámbito educativo argentino en particular. Tanto el principio de igualdad y no discriminación como el respeto a la diversidad, constituyen elementos del universo de la educación en ciudadanía vigente, como mandato fundante de la escuela pública (Siede, 2013). De modo que enfatizamos, la diversidad y la no discriminación remiten a principios del lenguaje de derechos humanos, una doctrina político-jurídica, que a su vez asume la forma de discurso educativo. En términos históricos, solo un par de años después de la sanción de la normativa en el año 1988, el término estaba disponible en el discurso escolar sobre la diversidad y los derechos de la niñez (Siede, 2016).

Considerando su temprana entrada y su nivel de despliegue como discurso político legítimo dentro de la escuela -algo que se constata por su hipervisibilidad en carteleras, talleres, proyectos, afiches- el paradigma de la no discriminación -y su contracara propositiva de la diversidad- resulta particularmente polisémico en el ámbito escolar. Precisamente, fue posible reconstruir esta polisemia como categoría social en uso mediante una aproximación antropológica sobre las concepciones de derechos de niñez y migración (Martínez, 2017) y su vinculación con las dinámicas de interacción y las identificaciones situadas en la escuela.

Desde este encuadre, hemos privilegiado la reconstrucción de las categorías de percepción sobre la discriminación como aspectos de prácticas y discursos en la cotidianeidad escolar. En tal sentido, las hipótesis que aquí presentamos son resultado del análisis triangulado de múltiples niveles del discurso educativo (la currícula y otros documentos institucionales, los discursos docentes, las relaciones cotidianas). Siguiendo premisas pilares de la antropología jurídica, nos interrogamos sobre la configuración concreta y situada de los paradigmas, procurando trascender la

Diálopos

sobre Educación

año 10 | número 19 | julio-diciembre 2019 | ISSN 2007-2171 
lente normativa y la dicotomía vulneración/efectivización de derechos como esquema de análisis de la realidad social (Fonseca y Schuch, 2009).

El material empírico que aquí se analiza fue producido en una investigación etnográfica ${ }^{2}$ dentro de una institución pública de nivel primario cuya matrícula reside principalmente en una de las villas de la zona sur de la Ciudad de Buenos Aires, con una importante proporción de población migrante. ${ }^{3}$ En el proceso de investigación, los interrogantes en torno a la categoría de la discriminación fueron cobrando forma a partir de la aproximación a las categorías sociales y a la documentación de "lo no documentado" desde la etnografía (Rockwell, 2011), descripciones de los docentes sobre el trabajo cotidiano, las percepciones sobre las familias, los niños y sus interacciones. En tal sentido, el encuadre metodológico general ha respondido a estrategias típicamente asociadas con la etnografía, como la observación participante, entrevistas abiertas o no directivas y conversaciones informales (Guber, 2004). El trabajo de campo se organizó en un primer momento, consultando descripciones en un sentido amplio sobre las condiciones de vida de la villa en general, los sentidos atribuidos a la inclusión escolar y la observación de las interacciones. Consideramos recurrencias en los discursos de los actores educativos, y nos centramos en las concepciones y prácticas de algunos de ellos/as en particular, mediante la triangulación de diversas situaciones y el seguimiento de un mismo grupo de docentes y niños/as en distintas situaciones.

Asimismo, hemos trabajado en triangulación con documentos institucionales y fuentes secundarias sobre discriminación. En adelante, el desarrollo del trabajo.

\section{La discriminación en el discurso escolar. Dilemas de los enfoques adultos e institucionales \\ El discurso educativo: sesgos institucionales y dinámicas cotidianas}

En los intercambios con los actores educativos, han sido frecuentes las descripciones y referencias a las condiciones de desigualdad estructural del ámbito donde se emplaza la escuela. ${ }^{4}$ Sin la dis-

2 Allí fueron entrevistados/as trece docentes y una de las directivas de la institución. Asimismo, trabajamos con un grupo de niños y niñas de entre 11 y 13 años, durante su cursada de sexto (2012) y séptimo (2013) grado de nivel primario. Para este trabajo se considera un total de 21 observaciones de aula con el mismo grupo, en su interacción con seis docentes (de acuerdo con el área de enseñanza), más cinco talleres de improvisación teatral con el grupo de séptimo grado. Además, realizamos un total de 18 entrevistas individuales y dos conversaciones grupales. Por otro lado, desde mayo de 2013 hasta noviembre de ese año, desarrollamos un trabajo etnográfico en un centro de apoyo escolar dentro del barrio, al que asisten algunos niños y niñas de esta escuela. Se preserva el anonimato de la localidad, las instituciones y todos los nombres propios han sido modificados.

3 Históricamente, la tasa de migrantes limítrofes o fronterizos se ha mantenido en un flujo sostenido y estable a lo largo de un siglo, entre $2 \%$ y $3.5 \%$ de la población del país (Pacecca, 2010). Actualmente constituyen 3.5 dentro del porcentaje de origen extranjero (en general) sobre el total de población migrante del país, 4.5\%. Dentro de la zona sur de la Ciudad de Buenos Aires, en particular en la jurisdicción específica donde trabajamos, la denominada Comuna 8, habitan 40,863 migrantes de América cuya mayoría son de origen limítrofe, 38,361 y 2,502 no limítrofes (del Perú y otros). Fuente: Censo Nacional de Población, Hogares y Viviendas, 2010.

4 Las villas constituyen asentamientos informales que concentran altos niveles de desigualdad y precariedad en términos de infraestructura general, servicios públicos, condición económica de los habitantes. Teniendo en cuenta distintos indicadores, este panorama ha ido empeorando sustantivamente con el cambio de gestión nacional, a finales de 2015 (Martínez, 2017). Del mismo modo, el giro político 
criminación no resulta una categoría de uso frecuente en la descripción de las dinámicas relativas a la inclusión escolar de esta población, ni para referirse a las condiciones de vida de la población migrante pero sí es mencionada cuando se alude a la conflictividad en las interacciones entre niños, y se la asocia a categorías de agresión verbal: "insultos". Es al preguntar por las relaciones entre pares que aparecen las situaciones de interpelación, es decir, cuando un niño despliega una categoría para "marcar" a otro o expresar un sentido despectivo sobre una categoría nacional, en particular jboliviano!

Vale mencionar que, además de componer el origen familiar de $80 \%$ de las/os niños que asisten a esta escuela, este colectivo enfrenta dinámicas particulares de alterización, como "otros", respecto de una versión hegemónica pretendidamente europea y blanca de la identidad nacional argentina, emparejados en este sentido con la devaloración y negación histórica de la población indígena (Grimson, 2006). Aunque también resulta -sobre todo en los últimos quince años- una categoría identitaria afirmada y reivindicada en distintos tipos de procesos organizativos de estos colectivos. Numerosas interacciones que hemos registrado en la escuela permitieron dar cuenta de esta complejidad de sentidos, y fundamentalmente el modo en que aquellos niños/as identificados como bolivianos - muchos de ellos nacidos en Argentina-, también son "marcados" en función de diacríticos como los estilos de español en uso del lenguaje o el color de la piel. Cuando se escucha la descripción de estas interacciones, se accede a las nociones un tanto ambiguas o "desentendidas" por parte de los adultos: "te está diciendo boliviano, ¿cuál es el 'problema'?"; así como la certeza de que en general los niños interpelados no responden a dichos discursos.

También son reiteradas las asociaciones discursivas con el parámetro disciplinar-como la bisagra entre lo esperado y lo disruptivo en la conducta de los niños-; son indisociables de la identificación de determinados niños como los "problemáticos", y a su vez, estos casos involucran alguna referencia a la figura de las familias. En los conflictos entre pares, la discriminación se nombra sucesivamente con categorías de trato interpersonal. Es que la discriminación se despliega como término para nombrar relaciones cuyo carácter conflictivo impone "observables", es decir, aspectos accesibles a la percepción directa (gestos y/o discursos de rechazo, interacción física violenta, segregación o distancia). Este foco, en el sentido de trato interpersonal que asume, permite explicar también usos exclusivamente locales de la discriminación, como cuando la directora de la escuela nos planteaba que "a los rubiecitos también los discriminan" o los docentes del apoyo escolar relataban las imágenes negativas de los bolivianos de la villa sobre los argentinos: "en la villa el discriminado es el argentino".

Por un lado, la discriminación como categoría del trato interpersonal parece deberle su parte al peso del enfoque jurídico sobre la misma, que tiende a su clausura como desigualdad de trato individual y no como desigualdad estructural entre grupos y posiciones sociales, es decir, de

se ha implicado en medidas legales y políticas criminalizantes para los migrantes, aunque la Ley de Migraciones 25.871 de 2004 -con un enfoque de derechos humanos- continúa siendo el marco legal de reivindicaciones vigente en el momento de escritura de este artículo, en octubre de 2018.

Diólo os 
estatus (Gutiérrez Rivas, 2014). Asimismo, fuimos registrando puntos de engarce entre algunas constantes de los usos sociales de la discriminación y modos deshistorizados que asumen el término en los discursos institucionales. Un caso paradigmático lo constituye la hipercirculación de la categoría de bullying, que ha ganado un lugar relevante en los discursos institucionales sobre la discriminación dirigidos a la infancia y la adolescencia. Centrado en el hostigamiento entre pares escolares y de edad, el bullying nombra -en inglés- acciones de violencia interpersonal de distinto nivel (verbal, físico, psicológico): está alcanzando el estatuto de sinónimo porque la discriminación se recorta, cada vez más, como una desigualdad de trato. No es cuestión de interpretaciones sino de la literalidad de las definiciones. En el documento elaborado conjuntamente por el UNICEF y el INADI, se afirma "Si discrimina no da compartir", "¿Qué es la discriminación? La discriminación es cualquier forma de trato desigual o maltrato hacia una persona o grupo" (UNICEF/INADI, 2016: 7), para luego vincularlo a la discriminación digital (sobre todo en redes sociales). Ya en la página diez del mismo, sin mediaciones, se habla del tema eje del documento como bullying y cyberbullying: la discriminación es reemplazada por el bullying como un sinónimo.

En este marco aparecen nuevos verbos también en las aulas, como relatan algunas docentes: como bulinear o ser bulineado. La alusión a formas de trato resulta un comodín que aparece en muchos otros documentos para definir la discriminación: a veces directamente como trato o maltrato (INADI, 2016a), otras asociando la discriminación a la violencia (INADI, 2016b), y en general, haciéndose eco de la definición jurídica de la discriminación como acto (INADI, 2011; 2016c). Sin embargo, hay ciertas desigualdades de trato que remiten a posiciones en la estructura social (como los migrantes) y otras que no. Destaquemos que no todo acto de violencia entre pares (o personas) reproduce relaciones sociales de poder, este aspecto político que divide las aguas; sin embargo, no es el centro de lo que se analiza en las interacciones entre los niños en la escuela. Hay que encontrar las razones para el protagonismo del bullying y su camuflaje como sinónimo en las bases de significado que lo vuelven posible, es decir, que preceden a la introducción de esta categoría: lo que se ha generalizado es una reducción interpersonal de la discriminación, la cual se vuelve particularmente poderosa en la escuela.

Asimismo, encontramos en el discurso institucional otro sesgo vinculado a las relaciones interpersonales como eje de la discriminación: los llamados aspectos actitudinales, la apelación a los valores, conductas y actitudes de trato frente a los demás. La tendencia a homologar contenidos conceptuales y actitudinales ya había sido señalada por Novaro, hace quince años (2002), para los contenidos curriculares sobre la discriminación. Los contenidos curriculares actuales de la Ciudad de Buenos Aires muestran que este sesgo mantiene vigencia, aunque con precisiones de mayor rigurosidad jurídica (Martínez, 2017).

Destacamos que la imbricación entre la persuasión de la conducta y el análisis político, no es privativa del discurso educativo ya que el lenguaje de estado incurre en los mismos solapamientos. Esto se presenta en documentos recientes que invitan a conocer una "Argentina 
intercultural", mediante la visibilización del aporte de grupos históricamente invisibilizados en Argentina, como los pueblos indígenas, migrantes o afrodescendientes. "Adoptar el paradigma intercultural implica perder el miedo a relacionarnos, interactuar con otros grupos, dialogando, aprendiendo a escuchar y a construir junto a quienes consideramos diferentes" (INADI, 2013; 2016a). Notamos aquí que una elaborada reflexión crítica, histórica y aparentemente antirracista, -pero de muy reciente y corto alcance en el discurso social-, es colocada en cadena de equivalencias con una persuasión actitudinal y de regulación de los estilos comunicativos. Sostenemos que esta operación discursiva, de partida, necesariamente tiene consecuencias pedagógicas. Como concepto, el diálogo obstaculiza inteligir la diversidad como proceso de democratización. Usado en explicaciones sobre el racismo y la interculturalidad, ofrece una cara lavada que mezcla la crítica a las versiones hegemónicas de la sociedad argentina "blanca" con la persuasión moral sobre la conducta hacia los otros. Establecidos algunos sesgos problemáticos en el nivel de los discursos institucionales, abordaremos en adelante su "operatividad" en la dimensión cotidiana de la institución escolar, específicamente en el modo de procesar conflictos nombrados como discriminación.

\section{El trato interpersonal y la posición política de los niños}

De acuerdo con las descripciones de los hechos discriminatorios y lo que hemos consignado, es innegable el peso específico de la verbalización "los niños se dicen". Este eje de verbalización se vuelve omnipresente, sobre todo en el aula, que en comparación con otros espacios de interacción dentro de la escuela "es una realidad hecha de palabras" (Díaz de Rada, 2008). Pero también hay una dimensión sensible, sensorial (olores, impresiones visuales, sonidos que se emiten o se escuchan, gestos de proximidad o alejamiento físico) que no puede ser divorciada de todo aquello que se verbaliza, dentro y fuera de los salones de clase. Para el tema que nos ocupa, se trata de una secuencia continua de aspectos no verbales que resultan verbalizados. En general, la inteligibilidad de las interpelaciones en la escuela se vale de un vocabulario de las emociones de los niños: angustia, bronca, vergüenza.

La presencia de las emociones en la interpretación de estos hechos se impone ante la proximidad física con los niños, los observables del sufrimiento con los que tienen que lidiar los docentes diariamente ante problemáticas familiares y sociales agudas en estos contextos: una de las maestras me relataba con detalle las vivencias de una niña de séptimo grado, cuya madre (migrante) ha sido condenada a diez años de cárcel por la figura de "mula" (tráfico de drogas). "Cuando [los niños] le dicen 'transa' se pone a llorar con una angustia; es una nena muy sensible". Reivindicar o silenciar una pertenencia se nombra mediante diferentes verbos en el trato interpersonal bardear, joder, molestar, cargar. En todos los casos, para los adultos y para los propios niños, las palabras tienen un lugar protagónico: "se/les dicen". Para empezar entonces, queremos situar el entendimiento institucional de las interpelaciones interpretadas como dis-

Diálo os sobre Educación año 10 | número 19 | julio-diciembre 2019 | ISSN 2007-2171 
criminación, en el plano de las verbalizaciones, el trato interpersonal y los efectos emocionales (gestuales, corporales, expresivos como el llanto o la confrontación física) que se perciben en las relaciones entre los niños/as.

Hay una acumulación local de registro de este tipo de interacciones que vuelve por demás representativas las escenas que nos relataron los y las docentes: "'callate boliviana', le decía como si nada", "Salí, no me toques, que me dejás olor". El olor, el rechazo, las imágenes despectivas que se pronuncian delante de los pares, forman parte de este "archivo" sobre la experiencia escolar de la discriminación que los acercamientos etnográficos vienen registrando desde hace por lo menos veinte años en Buenos Aires. Estas experiencias, desplegadas en un plano de proximidad física, constituyen prácticas entre niños en las que se "altera con violencia simbólica el cuerpo del otro" (Neufeld y Thisted, 1999). Por otro lado, estudios de otros países de la región, como Colombia, permiten suponer que hay condiciones para pensar comparativamente estos procesos: en tales contextos, la discriminación también remite a verbalizaciones de heterodesignación compulsiva en torno a la pigmentación de la piel, las autopercepciones y desmarcaciones, las relaciones de poder en torno a condiciones colectivas en las que los niños se ubican (el nosotros nacional o blanco) o a la inversa, se desmarcan. ${ }^{5}$ Hay intercambios verbales que solo es posible comprender asumiendo la clave racial, el modo en que los niños registran el color de la propia piel y la del compañero, observables que se despliegan como interpelaciones raciales solapadas, de modo risueño. Como hemos registrado decir muchas veces a Leo en el salón de clase: "quieto, negro". Aquí es el momento de explicitar que Leo tiene piel blanca (parte de los "rubiecitos", como me ha dicho la directora, aunque tiene cabello castaño); Ramiro, Adrián y Carlos, hijos de bolivianos, tienen la piel más oscura. También Simón: a él Leo se ha dirigido en varias ocasiones nombrándolo como "café". Pero se sabe que hay otros aspectos que denotan su pertenencia en la escuela, como las distintas tonalidades del habla española; en ese sentido, algunas niñas las pronuncian más marcadamente que otras, como Alina.

[Estamos en la clase de matemática, estoy haciendo fracciones con Eduardo]

Leo: Simón, mirá, acá estás vos, café. [Le muestra un frasco de café instantáneo que hay en el escritorio de la maestra. Simón le responde, pero no escucho].

[Alina responde a la consigna de la docente en voz alta, con una pronunciación que a Leo le parece muy nasal, que en tono burlón remeda una vocecita con la nariz apretada]

DOCENTE: ¿Qué está haciendo Leo?

EDUARDO: La está discriminando [por] cómo habla.

OTRO: Le está faltando el respeto.

5 Ya sea en la escolarización de niños afrodescendientes en Bogotá (Soler Castillo, 2013) o de niños peruanos en Chile (Pavez Soto, 2012), o niños colombianos en Quito (Sánchez Bautista, 2013), las interacciones discriminatorias al menos tienen la apariencia de un contenido similar a lo que se ha registrado en el contexto local, específicamente en el Área Metropolitana de Buenos Aires. 
DoCENTE: ¿Qué estás haciendo Leo? [en tono de reprobación]

LEo: Le estoy enseñando a hablar... [risas]

DoCENTE: Todos somos diferentes; unos hablamos rápido, otros lento [... y yo no puedo hacer la erre [...] mis alumnos no se ríen, como yo no me río de los chiquititos que no saben hacer las cosas... todos tenemos voces distintas.

CARLOS: Seño, ya son y cuarenta [hora del recreo]

DocENTE: Quiero uno que dé una reflexión sobre lo que hablamos. ¿Quién quiere decir algo? [nadie se ofrece] Eduardo nos va a decir qué piensa él...

EDUARDo: [hace como que toma un micrófono para dar un discurso, y riendo, pero con gesto solemne] Compatriotas...

DocENTE: [intentando cerrar, antes de que salgan al recreo] ¿Está bueno hacer burla? No...

Registro de clase, 5 de octubre de 2012.

Más allá de la observación en aula o los intercambios con niños y docentes en este espacio, gran parte de nuestras reflexiones se apoyan en el seguimiento de situaciones de interacción en un taller de improvisación teatral y distintas conversaciones informales, grupales e individuales con un grupo reducido de niños/as. En particular, abordando los usos de la categoría discriminación para nombrar situaciones de conflicto escenificadas por los niños, donde se expulsaba a los extranjeros -a los bolivianos en particular- de un ámbito laboral. Mientras algunos de ellos/as sostenían discursos de exclusión hacia los extranjeros, como Leo, Pamela y Alberto, los hijos de migrantes que protagonizaron la escena como Ramiro, se involucraron en discusiones y conflictos fuera de escena con el resto, retirándose finalmente de la situación grupal. La relación entre la polisemia de la discriminación como categoría social en uso, y el modo en que los niños/as construyen interpretaciones en torno a ella, fue analizada en detalle en trabajos anteriores (Martínez, 2017; 2018). Allí planteamos específicamente las huellas de saberes y matrices psicologizantes de sentido en las elaboraciones de los niños/as sobre los hechos de discriminación en la escuela. De hecho, el discurso escolar de la discriminación -tal como lo notan organismos de derechos humanos - APDH/INADI, 2010-, cobra forma particularmente moldeado por una mirada psicológica experta sobre el efecto emocional en los niños. ${ }^{6}$ En este punto hay que recordar que la lente "psi" no solo pertenece al saber experto en el ámbito escolar, sino que se ha convertido en sentido común sobre la infancia (Llobet, 2013). De modo

6 Valga acotar que en la nueva Ley Contra la Discriminación de la Ciudad de Buenos Aires, 5261/15, en su artículo 3 inciso c, se incluye esta dimensión emocional de las repercusiones de la discriminación en la tipificación de tales actos: “Las conductas que tiendan a causar daño emocional o disminución de la autoestima, perjudicar y/o perturbar el pleno desarrollo personal y/o identitario, degradar, estigmatizar o cualquier otra conducta que cause perjuicio a su salud psicológica y a la autodeterminación de las personas bajo cualquier pretexto discriminatorio".

Diólo@os 
que la investigación etnográfica nos ha permitido reconstruir la sistematicidad de las claves de interpretación individualizante sobre hechos que niños/as y docentes nombran como discriminatorios, y los condicionamientos que se implican para las elaboraciones que construyen niños y niñas en este contexto institucional (Martínez, 2017; 2018). En tanto tales matrices de sentido enfatizan las relaciones de trato en el plano de la proximidad física entre las y los niños en los hechos de discriminación, sostenemos la relevancia de hacer objeto de análisis especialmente a su proximidad política.

Particularmente en la escuela, como espacio de institucionalización de la infancia, la cercanía física y material, es también una proximidad institucional-política como alumnos y como pares de edad. En principio, enfatizar la posición institucional de la niñez en la escuela interesa para comprender el alcance específico que allí tienen términos y discursos sobre la diversidad (como las diferencias o el respeto) por ser imbricados a las posiciones y relaciones institucionales.

En Argentina, la democratización del trato hacia la niñez es un proceso vinculado primero a las redefiniciones de las pautas institucionales de la escuela con la reapertura democrática. La entrada del idioma de los derechos del niño, ya a finales de los ochenta, acompaña ese momento de redefinición de los paradigmas institucionales, a la vez que la sanción de la ley de infancia se implicó en lineamientos que hoy se ven en la currícula: nociones de trato del adulto, pautas democráticas de autoridad y disciplina. La convivencia, el respeto, el diálogo, son categorías pilares de los lenguajes democráticos con los que la escuela procesa -y promueve posicionarseante los conflictos.

[Los varones están riendo y conversando en voz alta mientras la docente intenta explicar. Interrumpe dos veces por las risas y demás, cuando sucede nuevamente, dice]

DOCENTE: El que no quiere se retira. Yo no quiero a ninguno afuera. ¿Saben lo que es estudiar? Es un derecho. Es un derecho que tienen, el aprendizaje. Respeten a sus compañeros, que también es su derecho. Es un derecho que tienen que aprender.

[lo repite varias veces. Los chicos dejaron de reírse, pero siguen con la atención dispersa. La docente termina de leer, y repasa los puntos principales con los chicos.

Leo viene a sentarse al lado mío, yo lo llamo con un gesto]

INVESTIGADORA: ¿Qué quiso decir la seño cuando dijo que es su derecho estudiar?

LEO: Quiso decir que está rebueno estudiar.

INVESTIGADORA: ¿Derecho... qué quiere decir con eso?

LEO: Que hay que estudiar para cuando sea grande ser alguien.

INVESTIGADORA: Pero derecho... ¿qué quiere decir esa palabra?

LUCAS: Que hay que estudiar... obligatoriamente.

[La docente sigue, dice]

DOCENTE: ¿Podemos trasladarlo a actividades escritas? 
CORITO: Noooooo.

DoCENTE: Saquen la carpeta de Lengua. [Se pone a copiar en el pizarrón].

[Me acerco a Yanet, le recuerdo el episodio de la señorita...no parece recordarlo mucho, se lo reproduzco y le pregunto lo mismo que a Leo, me dice].

YANET: Que tenes que portarte bien y estudiar.

[Vuelvo a mi banco, estoy en medio de Manuel, Jorge, Simón y Adrián. Les pregunto por la situación con la maestra ¿qué quiere decir que estudiar es un derecho?]

ADRIÁn: Que cuando nos da algo la seño, la tenemos que respetar.

SIMón: Que si queremos, podemos estudiar.

[En medio de este intercambio uno le dice a otro "para no ser burro", intercambian bromitas]. INVESTIGADORA: Y si decimos "tener derecho de ir al doctor"...

SIMÓN: Que te tienen que atender sin cobrarte.

Otro: Que tenes que ir.

SIMÓN: Que nadie puede decirte nada.

RAmIRO: [porque] Nosotros tenemos derecho a estudiar y tener una carrera cuando seamos grandes.

Registro de clase, 4 de octubre de 2012.

Lo que nos interesa de este fragmento no es la discusión pedagógica sobre los lenguajes democráticos como formas de autoridad, sino el sentido situacional y posicional que asumen, para las/os niños, ciertas categorías de percepción de los hechos escolares, como el respeto. En los intercambios con ellos/as, el derecho a estudiar aparece una y otra vez atravesado por múltiples caras: la relación entre la voluntad y la posibilidad (querer y poder), las interacciones institucionales en las que puede encarnarse un ejemplo cercano (que te tienen que atender sin cobrarte), el relato promocional (ser alguien y la profesionalización). En la mayoría hay una clave más bien automática de interpretación hacia el sentido de obligatoriedad, pero también de merecimiento. Hay que mirar esta imbricación entre lo obligatorio como convención social; la facultad que otorga un derecho a un individuo y lo que resulta una obligación para los niños (lo que dice la seño, que hay que estudiar obligatoriamente, etc.). Teniendo en cuenta que el respeto, por ejemplo, es uno de los términos que se despliegan ante las experiencias escolares y en los propios discursos institucionales, es central reconocer sus resonancias específicas, relativas a la posición política de la niñez en este ámbito institucional.

Sostenemos que la imbricación entre los lenguajes democráticos de la escuela y su cara “necesariamente" disciplinadora, es particularmente problemática para la inteligibilidad compleja de la discriminación como hecho social y estructural, sus intersecciones y distancias con lo que sucede en la escuela con las/os niños, es decir entre sujetos con una misma posición política. 
En este nivel de análisis de las interacciones comunicativas, hay que colocar la pregunta por las condiciones de posibilidad para que las experiencias de (mal)trato como migrantes o hijos de migrantes en la escuela sean asociadas a desigualdades sociales/estructurales hacia este grupo. Como hemos reconstruido en situaciones de conflicto en el taller teatral, los hijos de migrantes como Ramiro, despliegan contestaciones políticas en una escena donde un migrante disputa por trabajo frente a una empresa, pero tales contestaciones no aparecen al interpretar los actos cotidianos de sus pares en la escuela, que eran sostenidamente vinculados a faltas de disciplina y una biografía familiar disruptiva (Martínez, 2017; 2018). Sin embargo, esta matriz de inteligibilidad sobre los hechos de discriminación escolar resulta una clave de interpretación que también es apropiada por madres de niños/as que son violentamente discriminados, ${ }^{7}$ como el relato de una mujer boliviana ante lo que le expresa su hijo, con aflicción, sobre lo que vive en la escuela primaria. Cuando son los adultos los que "copian" -repiten- lo que dicen los niños, se destapa cómo se experimentan desde la infancia las desigualdades y jerarquías incrustadas en las estructuras sociales, económicas y culturales: el racismo, la subordinación material de los migrantes limítrofes, ${ }^{8}$ la negación de la membresía nacional a los hijos de bolivianos.

"Mamá ¿por qué nací de este color? ¿Por qué me dicen boliviano si soy argentino?" los chicos que lo molestan le dicen: "Vos naciste para servirme".

La mujer me dice que ante esto considera que es importante "hablarles de dónde vienen, que valoren y reconozcan... [que tengan] respeto por su origen".

Cuando pregunto a qué atribuye esto de parte de los niños, me habla del caos familiar de la casa (que ya conocen a quienes discriminan); aunque una salida es "hablar con los padres".

Conversación en Tribunales. Espera del inicio del Juicio por el Taller Textil de Luis Viale. ${ }^{9} 18$ de abril de 2016.

Puede reconocerse una concepción de sentido común que se cuela en las impresiones de docentes y padres migrantes por igual: la atribución de las formas agresivas o despectivas de los niños es asumida como "copia" de prácticas incorporadas en el seno familiar. Hay una lente disciplinar con la que se reflexiona sobre lo que hacen y dicen los niños, desde la clave de la biografía

7 Un conocido en común, familiar de los protagonistas, me había presentado como alguien que trabajaba la discriminación en la escuela, ya que esta mujer buscaba orientación por lo que le pasaba a su hijo en una escuela primaria de la zona sur de la Ciudad de Buenos Aires, en una jurisdicción distinta a donde trabajamos.

8 Unos meses antes, en octubre de 2015, durante un encuentro en la Universidad de Buenos Aires, el referente de una organización de jóvenes migrantes bolivianos comentaba interpelaciones hacia niños de origen boliviano como "esclavos" en una escuela de Flores, Ciudad de Buenos Aires.

9 En un caso emblemático de la explotación laboral de la población migrante, un incendio en el taller se produjo en 2006 en la zona sur de la Ciudad de Buenos Aires, en el que fallecieron cinco niños y una joven embarazada. 
familiar que nutre estas clasificaciones sobre los alumnos. Es llamativo advertir que estos aspectos también pueden estar presentes en el discurso académico sobre el tema, donde se reproducen categorías de análisis propias del sistema escolar (López, 2011).

El presupuesto de que lo que dicen y hacen los niños es una copia de lo que hacen los adultos de referencia, remite por un lado a una noción interpersonal de la discriminación -que se traduce en actos verbales o prácticas-. Pero, también es una interpretación generalizada que se dispone para interpretar las distintas formas de malestar que expresan niños y niñas en la escuela. Hay aquí las huellas de una clave de interpretación sobre la reproducción de la violencia familiar en los nuevos vínculos del sujeto, propia de la matriz"psi" (Llobet, 2011). Es un horizonte, nuevamente, de trato interpersonal y de violencia, accesible a la percepción directa. No es sorprendente que sea en la escuela donde la discriminación se enmascara específicamente con trazos de invidualización, arbitrariedad, violencia de un fuero interno del sujeto.

SANDRA: A principio de año tuvimos mucha discriminación entre ellos, pero [después] logramos un montón de cosas en cuanto a lo humano. No sabés lo que era al principio "cállate boliviana. Salí, no me toques que me dejás olor". Igual, al chico que dijo esto, ¿sabes cómo le rebatimos la mala onda? "Vos cállate Aguayo, ¿de dónde viene tu apellido?". Se quedó mudo.

INVESTIGADORA: ¿Y de dónde viene?

SANDRA: Hay veces que tenés que ser así. No sé de dónde viene esa discriminación que él tiene. INVESTIGADORA: No, el apellido digo.

SANDRA:Y, me parece como... me suena a boliviano, Aguayo [...]

Entrevista a Sandra, docente de sexto grado. 9 de octubre de 2013.

Además del enmascaramiento del hecho social de la discriminación, podemos interpretar en este intercambio algo que ayuda a comprender la persistencia del sesgo de la persuasión actitudinal en este tema, y es que no colisiona con lo que evidentemente sigue presente en la escuela, entre los propios educadores: la estructuración jerárquica de las diferencias (étnicas, raciales, nacionales, de clase). Asimismo, la observación de que las verbalizaciones de los niños se modifican "con el paso del tiempo", luego de intervenciones sostenidas de los educadores, nos ha sido planteada en numerosas ocasiones.

Es relevante señalar en este sentido, que la mirada individualizante se complementa con el sesgo actitudinal que comienza en los propios documentos institucionales. La polisemia alcanza -no casualmente- algunos términos vinculados a estos lenguajes democráticos: el respeto, como término vinculado a la regulación escolar, también va en un sentido contrario al que le dan las personas migrantes -o sus hijos en la escuela- ante estos conflictos. Para los migrantes, el respeto tiene que ver con el merecimiento de un derecho en condiciones de igualdad, o la 
reivindicación de un origen o pertenencia. El respeto en las interacciones cotidianas de la escuela tiene resonancias específicas relativas a la posición de autoridad: más bien condensa efectos tácitos de censura verbal.

La vinculación de la diversidad a un plano actitudinal tiene un efecto de desplazamiento que puede rastrearse también en lo que hemos mencionado para los discursos institucionales. Es un problema derivado de mezclar concepciones de alta politicidad histórica contra la "argentina blanca" oficial, con apelaciones dulcificadas a ser abierto y escuchar al otro. El riesgo es que la discriminación se encapsule como un hecho de la práctica (individualizada) hacia los demás, y no como la internalización de relaciones de poder. La reflexión pedagógica debe preguntarse cómo la crítica de una forma de trato a los demás se vincula (o no) a una crítica social del sistema. En este último caso, se podría decir que el juicio moral sobre el daño que se hace a otro y la bifurcación básica entre lo bueno y lo malo, se articula a la inteligibilidad de una relación de poder.

Porque la internalización de jerarquías no siempre se traduce en actos. En el trabajo de campo hemos relevado numerosas situaciones donde los hechos "discriminatorios" se centran en un grupo de varones y las dos niñas que suelen frecuentarlos. Deliberadamente, varias niñas (como Sandra, Alina y Sonia) pidieron realizar talleres entre niñas y tuvieron como eje de conflictos, a partir de la misma consigna, a las mujeres. Allí hablaron de vecinas, la crianza de los hijos, vivencias de un grupo de amigas. En dichos contextos de interacción, claramente no tuvieron lugar interpelaciones como las que relevamos en muchas situaciones. Es decir, analizar las interpelaciones de clase y nacionales en la escuela ha empujado necesariamente a detenerse en lo que hacen y dicen los niños. Entonces hay un plano de la puesta en acto, la "muestra" de verbalizaciones que tienen como protagonistas a los varones. Sin embargo, la internalización de jerarquías sobre los extranjeros puede correr paralela a lo que se considera adecuado para el plano del trato interpersonal.

INVESTIGADORA: Bueno, yo me acuerdo que uno de los personajes que hacía de extranjero decía: "Bueno, yo voy a hacer una denuncia por discriminación".

Pamela: Claro, hacía una denuncia porque nosotros no lo queríamos ahí, por eso, la empresa, nosotros no podemos hacer nada si esas órdenes nos dieron a nosotros [...].

INVESTIGADORA: Y el extranjero ¿cómo sabe que tiene que hacer una denuncia?

PAmela: Lo habrá escuchado, habrá hecho otra denuncia, o le habrán dicho: “Anda a quejarte a la comisaría".

INVESTIGADORA: ¿Y la policía cómo sabe que le tienen que tomar esa denuncia?

Pamela: Porque es un derecho, creo. Que a los extranjeros no los tenemos que echar, supuestamente.

INVESTIGADORA: [...] porque vos decís que no se los echa porque es un derecho, pero el señor de la empresa igual... 
PAMELA: El señor habrá querido entrar a otro país y como no tenía dónde trabajar, no le deja-

ban... y habrá hecho lo mismo.

[...]

INVESTIGADORA: ¿Y para vos será así?

Pamela:Y no tienen que entrar acá... no es de mala [...] es que no me gusta... tienen que ir a su país.

InVESTIGADORA: Vos decís "no es de mala [...]", ¿alguien te dijo?

PAMELA: Sí... dicen que soy mala porque digo eso.

INVESTIGADORA: ¿Qué hace un malo?

Pamela: Yo digo eso, pero después me arrepiento porque no le voy a decir "andate a tu país"

porque se sentiría mal, y si se lo digo soy mala.

Entrevista a Pamela. 6 de diciembre de 2013.

Está claro que negarle los derechos a los migrantes no es una cuestión de falta de información sobre la legislación vigente. La prescripción como convención social "no los tenemos que echar", se completa con una categoría que marca distancia con dicha prescripción, supuestamente. Este posicionamiento de Pamela sobre los pares que se sienten mal cuando ella es mala -es decir, cuando dice lo que piensa sobre los extranjeros- es posterior a los conflictos e intercambios desencadenados en un taller con la investigadora. En sus reflexiones resuena el eco de lo que había conversado con sus pares y con la adulta, sobre el efecto emocional de la situación de Ramiro, hijo de migrantes que se fue enojado -"con bronca" dijo específicamenteal escuchar verbalizaciones discriminatorias hacia los extranjeros, y luego sostuvo distancia con sus pares durante unos días. Sin embargo, más adelante en la entrevista, Pamela agrega que ni los propios niños -incluso los nacidos en Argentina- merecen estar en la escuela pero que no lo dice, tampoco, para no ser mala y que no se sientan mal. Es importante reflexionar sobre la brecha que parece pronunciarse entre la verbalización que se considera inadecuada para el trato interpersonal, y la tenaz persistencia de la jerarquización por nacionalidad, que la niña considera legítimo ejercer incluso hacia los propios pares de edad y su derecho a la escuela.

En las entrevistas recordábamos el dilema suscitado en la escena del taller. Todos los hijos de migrantes entrevistados sostienen, como desenlace de la situación conflictiva del taller que les presento, una suerte de "sujeto colectivo": un grupo de extranjeros que reclama, una marcha, una protesta. En un caso nos hemos encontrado con un nivel de argumentación y afirmación de derechos sugerente. Entre todas las reivindicaciones que sostuvo Sonia en las entrevistas, -acerca del gobierno de Evo Morales, la defensa de derechos en marchas y manifestaciones-, destacó su derecho a vivir en Argentina porque ella misma es migrante, además puso en relación la situación teatral del taller con la arbitrariedad de los actos discriminatorios. 
INVESTIGADORA:Te cuento cómo sigue la escena. Uno de los trabajadores les dice:"Voy a hacer una denuncia por discriminación".

SoniA: Discriminación porque no le quieren dar trabajo a un extranjero [...]. Solo digamos un argentino y viene un boliviano, digamos. Entonces revisan a los dos, y los dos están a la altura como para el trabajo ¿no? Pero primero escogen al argentino, con decirte que no quieren darle trabajo al boliviano [...].

Entrevista a Sonia. 2 de diciembre de 2013.

En las palabras de Sonia resulta difícil encontrar rastro alguno del tono generalizado (siempre hay excepciones) con el que se habla de las nacionalidades como conflicto en la escuela: allí lo que resuena como arbitrario es la jerarquización que se desprende de las palabras de los niños “ ¿cuál es el problema?". En cambio, el argumento de Sonia es claro: la nacionalidad se usa arbitrariamente como criterio contra un boliviano "a la altura" -comparado con un argentino- para un trabajo. Este manejo de la argumentación sobre lo arbitrario de la nacionalidad como mecanismo político, va a contracorriente de lo que sostenidamente se comunica desde la escuela cuando los niños ponen en acto interpelaciones despectivas o burlescas. Parece una elaboración construida en el marco de su trayectoria por fuera de la escolaridad -recordando también que su madre es militante en una organización-. Cómo se reconstruye entonces el nexo entre la discriminación en la escuela y lo que se comprende políticamente sobre ella como hecho social, es una pregunta por demás relevante sobre las concepciones de los hijos de migrantes. Porque, aunque se afirmen concepciones de derechos sobre los extranjeros -como también parece sostener Alina-, ello no se vincula a posicionamientos sobre hechos de discriminación similares a los que ella vive en la escuela.

INVESTIGADORA: ¿Y para vos qué es lo que corresponde?, ¿cómo deberían ser las cosas? Suponete, vos tenes que decidir cómo termina la escena: "No, pero nosotros queremos trabajar", y la de la empresa: "No, acá solo argentinos".

Alina: Bueno, en esa situación puede meterse algún empleado de la empresa y decir: "Nosotros necesitamos un empleado extra para trabajar".

INVESTIGADORA: ¡Ah, mirá! Pero imaginate que el dueño de la empresa diga: "No, el requisito es [que sea] argentino".

Alina: A veces el jefe estaría mal. Porque a él no le gusta estar con gente de otro país. Entonces estaría mal.

INVESTIGADORA: ¿Cómo te das cuenta que está mal?

Alina: Porque, no sé. Yo tuve un amigo negro y todos empezaron a burlarse de él. Y por esa razón otras veces no quise estar con gente extraña. 
INVESTIGADORA: ¿Y cómo es la gente extraña?

Alina: No sé, un chino que tiene los ojos caídos. Y un negro que es de África o de Brasil, y porque una persona hable en inglés y no lo puede entender... y los españoles también son extraños [...] porque le ponen muchas zetas y esas cosas [cuando hablan].

INVESTIGADORA: Ahí cuando la empresa les dice que no porque no son argentinos ¿hay algo que se pueda hacer como [...]? ¿Cuál debería ser su reacción?

Alina: Bueno, ellos podrían planear un grupo de extranjeros y decirle al gobierno: “Nosotros no tenemos trabajo y ustedes sí" [...] y por eso, solo armar cortes para que les den otro trabajo.

Entrevista a Alina, 5 de diciembre de 2013.

De algún modo, está hablando en tercera persona sobre hechos que la conciernen directamente: Alina tiene un estilo de español que es burlado por sus pares, tiene los ojos rasgados y la piel morena, en torno a todos estos diacríticos es identificada como boliviana habiendo nacido en Argentina. Habla en tercera persona de hechos similares a lo que le pasa a ella en la escuela; en principio, podría interpretarse como que no acepta para sí misma la descripción que le asigna a alguien "extraño" a los argentinos. Resulta importante ver que su posicionamiento parece convalidar, o al menos no cuestionar, la desigualdad de trato hacia los negros. Ello no se alinea con un discurso xenófobo, en principio manifiesta que los extranjeros pueden reclamar un trabajo negado. "Estar mal” es una misma categoría de percepción para dos hechos: la exclusión laboral a un extranjero y la segregación a un par negros. Pero si primero es el jefe que niega el trabajo quien está mal, cuando se refiere al estar mal como un hecho de quienes excluyen a pares (un amigo negro), el excluido es "gente extraña", y convalida la segregación y la distancia. Lo que está mal de la situación que ella asoció con (otro) acto de exclusión, se desplaza: "no quise estar con gente extraña". El posicionamiento de Alina diverge de los posicionamientos de exclusión mediante una forma arquetípica social contra los migrantes; pero ello no se traslada a un posicionamiento sobre hechos más cercanos, "arquetípicos", de lo que vivencia ella en la escuela.

Volver al trato interpersonal y al impacto emocional como aspectos constitutivos de los hechos nombrados como discriminación, sirve para advertir que se trata de aspectos generalizables a cualquier tipo de conflicto y relaciones de poder entre niños en la escuela. Lo que debería dividir las aguas es que solo algunos conflictos entre pares reproducen relaciones sociales de poder. No todos. Por ello es que cuanto más se unifiquen los conflictos de discriminación en torno a reglas "internas" de convivencia (saturadas de disciplina), menos podrán esclarecerse pedagógicamente las relaciones y distancias entre las vivencias institucionales y los procesos sociales.

Es central ver que hay aspectos del "código institucional" para interpretar lo que expresan los alumnos, que no solamente saturan las interpretaciones sobre los niños que discriminan, sino las emociones, reacciones y demandas de los que son discriminados. Un ámbito educativo 
como "el apoyo escolar" en el barrio, está plagado de diferencias y distancias respecto de diversas cuestiones en relación con la escuela, un nivel de reconocimiento de la posición de los migrantes en la sociedad, etc. Sin embargo, la discriminación como hecho entre los niños es asociada a un universo de sentidos similar: la individualización, la equiparación de calificativos.

FeDERICA: [dirigiéndose al grupo] Quiero meter un bocadillo. Ana vino a compartir algo y... ¿querés contarlo?

AnalíA: Estaba en la iglesia y me caí al piso... Sentí que dios hablaba conmigo en lenguas... me liberé [...], cuando me fui a dormir me liberó de la angustia que sentía de lo que me dicen en el colegio [porque] me dicen ciruja ${ }^{10}$... [mira a Lucas, sentado junto a Juan y los otros varones del grupo] Te estoy hablando a vos Lucas, porque yo soy evangélica.

[Lucas mira para abajo, nadie habla. Silencio]

Federica: Perdón... independientemente de que uno comparta o no [sobre la religión] ¿está bueno reírse si es diferente [...]? Alguien que viene con anteojos... o alguien que dice "eh, vos, boliviano"...

JuAN: Ey, sí, yo soy; ja mí nadie me maltrata!

Federica: Eeepa...

MARIELA: Es muy significativo lo que dijo Ana [poder hablar sobre] qué es lo que generó angustia...

FEDERICA: Hay gente que se saca la angustia jugando al futbol [...] o pintando un cuadro... ¿Qué hacen ustedes cuando están angustiados? [algunos comentarios superpuestos] ¿y alguien alguna vez se metió abajo de la cama...?

Observación de clase "ronda" en Apoyo Escolar, 26 de agosto de 2013.

La angustia de Analía, ${ }^{11}$ una niña pobre que es llamada ciruja, se vincula con una noción angelada de la discriminación escolar, donde usar anteojos sirve para hablar de los niños llamados cirujas o bolivianos despectivamente, como diferentes. Sobre todo, lo relevante es ver cómo la emoción que verbaliza Analía se traduce en una angustia abstracta, generalizable a cualquier otra: "¿Qué hacen cuando están angustiados?" Yendo a las vivencias en la escuela, las injurias y reacciones que se desencadenan ante signos de violencia verbal contra los migrantes y/o los pobres, entrecruzan aspectos biográficos con la posición en la sociedad. Mientras en muchas situaciones de la escuela también hemos registrado el modo en que los adultos/as ${ }^{12}$ tienden a

10 En México se traduciría como "pepenadora". Nota de la editora.

11 Analía nació en Argentina, sus padres son argentinos. Tiene 12 años.

12 Entre quienes nos incluimos, lo cual hemos hecho objeto de análisis al reflexionar sobre los cruces entre la investigación y la intervención docente en los espacios del taller de improvisación teatral (Martínez, 2017). 
equiparar los calificativos que verbalizan los niños/as (gordo, dientón, boliviano), la complejidad de la experiencia de los niños y niñas, sin embargo, condensa la reacción a una ofensa personal, familiar y a la vez colectiva: resuena contra múltiples sentidos de pertenencia a la vez.

Esta forma de traducir las emociones, en el contexto resulta complementaria de la neutralización del aspecto político de los efectos en los niños y las niñas, de sus malestares y vivencias. Un camino posible para comprender este tipo de intercambios políticamente ambiguos y hasta negadores de lo que se conoce del entorno, es el niño al que se le habla en las interacciones pedagógicas: cómo cierta imagen recortada de niño "universal" se proyecta en el mismo momento en que se habla con ellos y ellas (Martínez, 2017), cuando sin embargo se escuchan sus demandas como niños y niñas que no encajan en esa figura angelizada.

Haciendo un intento de cómo sería escuchar las emociones de los niños/as de otro modo, queremos advertir que otro aspecto de la conversación grupal analizada es cómo se interpreta la afirmación de Analía sobre ser evangélica. Consideramos central preguntarnos por el recurso que este marco simbólico está ofreciendo a una niña "pobre" que inmediatamente antes había expresado malestar por ser llamada ciruja en la escuela. Escuchar tal asociación discursiva entre lo que no se quiere ser (nombrado) y la afirmación de "ser" algo: "porque yo soy evangélica". En sintonía, Juan responde confrontativamente al ser nombrado como boliviano: "sí, yo soy". En el plano de las interacciones, la heterodesignación no es siempre una interpelación directa, que es lo que se capta como acto verbal "políticamente incorrecto". Las heterodesignaciones políticas cargan con significados que rebalsan este estilo de intercambio verbal: no pueden ser reducidos a una interacción compulsiva, sino que implican significados que se construyen y (re)producen mediante la pronunciación de un verbo que se generaliza: ser. Ser alguien a través de la profesión, que hemos reconstruído como retórica socialmente extendida, no es la única forma en la que el ser se verbaliza. De hecho, es más probable que esta retórica se despliegue frente a un adulto, porque se reconoce su legitimidad institucional, pero eso no quiere decir que se limite a ello. Durante todo nuestro trabajo de campo hemos relevado la complejidad de estas verbalizaciones sobre lo que se "es", en el marco de distintos tipos de interacciones entre los niños y niñas. Al escuchar dentro del aula que a algunos niños se los interpelaba diciéndoles que venden pan, Adrián nos explicaba: eso porque su mamá es pobre. $\mathrm{O}$ en el patio de la escuela debatiendo en grupo con la investigadora, cuando la solidez argumentativa de Ramiro sobre un caso judicial fue contestada con varios comentarios de aprobación y/o admiración de parte de sus pares: bueeno vos estudiá para ser policía, le sugería Carlos. Asimismo, en el contexto de los talleres de improvisación, se desplegaban intercambios en torno a ser boliviano, pero también otras categorías de identificación, como ser indio. 
En el patio, Amanda y Pamela están sentadas entre otros niños, "espectadores" mirando a Ramiro y Eduardo. Intercambian risas y bromas mientras esperan que los "actores" comiencen a hablar.

Amanda y Pamela conversan con Ramiro, Amanda le pregunta ¿vos sos indio? [Se ríen]

Registro de Taller 04/11/13.

En el idioma español, ser -al igual que estar y parecer- es uno de los verbos copulativos; se trata de verbos que fijan un predicado nominal del sujeto, es decir, que vuelven equivalente el atributo (del predicado verbal) con el sujeto. ${ }^{13}$ Ser es un verbo presente en las interacciones comunicativas entre los niños y niñas y lo que sirve para comprender el sentido de las heterodesignaciones políticas es su inscripción en un flujo más amplio de identificaciones y posicionamientos. La negociación, apropiación o disputa entre lo que se es, lo que se debe/ quiere ser, y lo que no.

\section{Las paradojas en la configuración situada del principio de no discriminación: ¿un trasfondo disciplinar?}

El eje de los hechos que son nombrados como discriminación en la escuela adquiere un carácter centralmente verbal: una desigualdad en los posicionamientos públicos sobre la categoría de identidad (nacional, racial, de clase, etc.) entre quienes la nombran como identificación compulsiva, a veces hasta como lenguaje de odio, y quienes son objeto de ella: lo que se hace sistemático en los contextos de interacción es la asimetría entre las formas de pronunciación. Si hay algo que hemos registrado en el análisis comparado de las interacciones verbales entre los/as niñas es que los significados que se despliegan en torno a la extranjería son indisociables del efecto performativo que generan en las relaciones de poder entre pares. Pero el contenido de las interpelaciones no es ni verdadero ni falso (Butler, 1998); es una heterodesignación cuyo efecto va asociado al sentido que se logra instalar sobre una categoría. Las heterodesignaciones compulsivas entre niños cargan con un efecto de mostrar los sentidos negativos con los que se carga a una categoría de identificación. Sin embargo, las percepciones sobre las diferencias no son reductibles a este estilo de verbalización, sino que implican interrogantes y dilemas sobre lo que se es, y lo que no se quiere/debe ser. Ello no implica linealmente desmarcaciones sino, también, apropiaciones y reivindicaciones, como planteaba Juan: "sí yo soy".

No obstante, en la escuela los discursos adultos superponen términos de experiencia sobre las relaciones de trato -como el respeto, la convivencia, las burlas, por ejemplo-, a las categorías

13 Definición de verbo copulativo Real Academia Española: <http://www.rae.es/diccionario-panhispanico-de-dudas/terminos-linguisticos> 
de percepción de las diferencias (como formas de hablar, color de piel) en su estructuración jerárquica social e histórica. Como aquellas percepciones que se construyen en la asociación de una piel trigueña y el café o la condición de "indio" (serviría pensarlo como la relación entre las frecuencias AM y FM). La posibilidad de vincular estos significados institucionales a relaciones sociales de desigualdad, depende del volumen que se le asigne a la reflexión sobre los hechos estructuralmente discriminatorios, resaltando que las verbalizaciones de los niños se vinculan, pero no se equivalen a ellos.

Como hemos notado, ese volumen se diluye entre los significados ambiguos y el procesamiento actitudinal-disciplinar de los hechos. De modo que el registro verbal de las proposiciones y la persuasión actitudinal es fundamentalmente adulto. En este punto, la superposición, como falta de sintonía, también está mediada por relaciones y posiciones de autoridad. Esto lleva a preguntarse si en determinadas situaciones lo que se instala con las frases propositivas, el "respeto" $u$ otras sobre el trato interpersonal (como no burlarse) frente a experiencias discriminatorias, es un efecto de regulación de las prácticas de verbalización sobre la jerarquía de las diferencias -que es central insistir, no siempre son discriminatorias-. Frases que hemos registrado en las comunicaciones adultas hacia los niños en situaciones de conflicto discriminatorio (como "todos somos diferentes"), no interaccionan pedagógicamente con los significados de los niños, sino que reproducen la versión institucional sobre la igualdad. En particular, las diferencias adquieren un sentido situado, disciplinar, como contestación a prácticas verbales de discriminación. Es decir, que no equivalen al significado que lo diferente asume en general en las interacciones verbales cotidianas de la escuela, donde es un término comparativo y no propositivo (por ejemplo, en clases que hemos observado donde el docente del grupo comparaba la legislación laboral en distintos tiempos históricos diciendo "antes era diferente"). La verbalización de las diferencias en su materialidad (los negros "café", por ejemplo), surge de "comparaciones que ya están hechas", diferencias que ya han sido registradas por los niños: el asunto es la jerarquía entre lo que se compara, la relación de poder entre las diferencias. Las prescripciones de lo que todos somos, no parecen tocar esta fibra política de la diversidad, ni tampoco conectan con la verbalización del ser en las interacciones comunicativas situadas de los niños. Como definiciones propositivas, desanclan las diferencias -lo que se es o no se quiere ser- de su sentido performativo, el efecto de "mostrar" las jerarquías sociales. En esas frases propositivas, la verbalización institucional de lo que se es deja a la diversidad y los derechos dentro del orden de la ficción jurídica de la igualdad: opaca su inteligibilidad como demanda de democratización y crítica social.

Recordemos que esta superposición entre las categorías lingüísticas de trato y las que remiten a interpelaciones sobre categorías de identificación, cobra forma en un marco institucional que dispone, con cierta sistematicidad, de claves de interpretación sobre la discriminación como hechos entre alumnos: los saberes psicológicos, las normas de trato institucional y convivencia. Esto es lo que nos lleva a postular un interrogante sobre la existencia de un trasfondo 
disciplinar del discurso contra la discriminación y el respeto a la diversidad en la escuela. En principio, esta hipótesis ofrece una explicación sugerente para un hecho que, de tan obvio, pasa desapercibido: de todas las estrategias desplegadas en el trabajo de campo, no obtuvimos registro alguno de niños/as que solventen argumentativamente sus conflictos con pares en torno a la discriminación mediante las categorías institucionales de la diversidad (diferencias, respeto, convivencia). Ya que se habla tanto de que las interpelaciones discriminatorias tienen que ver con lo que repiten los niños/as, hay que preguntarse qué es lo que ellas/os no quieren repetir de los adultos y los discursos institucionales. Deliberadamente, este discurso bienintencionado de la diferencia no es apropiado por los niños migrantes e hijos de migrantes. Su clave adulta, tácitamente disciplinadora y políticamente ambigua es, precisamente, lo que obstaculiza que los niños puedan incorporar a las diferencias en alguna contestación política. Si se ha planteado la falta de condiciones para que las/os niños migrantes e hijos de migrantes pongan en relación lo que viven en la escuela con procesos que atraviesan al colectivo (Novaro, 2011), sostenemos que una parte de este problema remite a las categorías de percepción que se disponen sobre las experiencias discriminatorias escolares. Ya que están profundamente imbricadas a los códigos institucionales de trato individualizado sobre los alumnos.

Este trasfondo también atraviesa y condiciona la escucha de las emociones y vivencias que expresan niñas y niños. El trasfondo disciplinar obtura dos aspectos significativos: que estas emociones que se viven en el ámbito escolar, en la infancia, puedan ser conectadas con una memoria de injurias y elaboraciones colectivas. Segundo, el entendimiento de que las verbalizaciones discriminatorias de los niños no resultan totalmente equivalentes a la discriminación estructural como hecho político. Entremezclado con los posicionamientos institucionales hacia los alumnos, el discurso contra la discriminación y de respeto a la diversidad se divorcia del sentido político que asume para los colectivos: cuanto más se lo utiliza en relación con normas locales escolares, más grande es la distancia entre lo que activa en la escuela y lo que moviliza políticamente fuera de ella más tendrá que ver con las pautas de contrato institucional o la "corrección política", y menos con una contestación a la desigualdad existente, las jerarquías incrustadas en las estructuras sociales. Finalmente, el horizonte disciplinar obstaculiza el entendimiento del problema educativo y político en las interacciones comunicativas entre las y los niños: la reproducción de jerarquizaciones sociales. Correr esta lente abre a una pregunta pedagógica y política sobre la fuerza con la que se internalizan esquemas de poder en la infancia. Ello podría explicar algo más complejo sobre los actos de los niños, que desde luego no ocurre solo dentro de las paredes de la escuela: por ejemplo, el nivel de identificación con el poder (por más situacional que sea) necesario para imponerse ante un par tratándolo de esclavo: "vos naciste para servirme". 


\section{Conclusiones}

Hemos relevado algunos aspectos de las definiciones institucionales sobre la diversidad y la discriminación que imprimen resonancias específicas y problemáticas en el contexto escolar. Quisimos advertir, en este sentido, que lo que está siendo objetivado (cada vez más) como discriminación en el discurso educativo, son las múltiples condiciones sociales que se involucran en las formas de (mal)trato entre pares. Ello necesariamente se divorcia del sentido colectivo e histórico del principio de respeto a la diversidad y la lucha contra la discriminación. A la vez que obstaculiza la comprensión compleja de los propios actos, sus distancias e intersecciones con los hechos estructurales. Siguiendo este análisis, postulamos que enfoques reduccionistas como el bullying promueven nociones deshistorizadas de la violencia y los conflictos escolares.

Nos detuvimos en la persistencia de jerarquizaciones, su imbricación ambivalente con juicios sobre las formas de trato e invidualización. En este marco es que nos preguntamos por los sentidos tácitos, es decir, no explícitos ni conscientemente buscados, que adquieren los usos del discurso escolar sobre la discriminación y sus efectos paradójicos. Dejamos planteado el interrogante sobre la distancia con la que los y las niñas experimentan los significados institucionales y adultos sobre las diferencias, ya que este discurso no resulta apropiado en las interacciones entre pares, ni en las interpretaciones que los niños y niñas construyen sobre los hechos discriminatorios. Más bien lo que pudimos reconstruir son bifurcaciones entre la interpretación de lo que se vive en la escuela y la comprensión de la discriminación como desigualdad, que atraviesa a los migrantes como colectivo.

Mientras la escuela comunica -con relativa sistematicidad- un mensaje político claro que reprueba las verbalizaciones discriminatorias, deja ver (a las y los niños) la profunda ambigüedad que configura a este posicionamiento institucional, que depende de los atravesamientos ideológicos y las concepciones de cada docente. Son reflexiones que sugieren se ha generalizado la visualización de la forma del discurso discriminatorio, mas no la conciencia crítica sobre las relaciones históricas de poder que éste encarna. Vale remarcar que estas reflexiones, trabajadas entre coyunturas políticas en transición y de progresiva hostilidad hacia la población migrante en Argentina, nos preocupan particularmente en un contexto donde la legitimidad material y simbólica de los derechos, así como el principio básico liberal de igualdad y no discriminación, resultan horadados por las administraciones de signo neoliberal en Argentina y la región latinoamericana.

Por lo dicho, escribimos estas reflexiones también con la deliberada preocupación ante el incremento del lenguaje de odio y la urgencia por fortalecer el aporte pedagógico y democrático del discurso contra la discriminación en el ámbito público. Al haber registrado algunos sesgos institucionales y jurídicos que aumentan los efectos paradójicos del discurso escolar sobre la discriminación, nuestra aproximación permite fundamentar la necesidad de redefinir teóricamente el tema. Proponemos inscribirlo en una pregunta más amplia y compleja sobre la 
relación entre las identificaciones y las concepciones de derechos en la infancia. Sin embargo, las configuraciones concretas del principio de igualdad y no discriminación se han estabilizado en un trasfondo disciplinar que satura de sentido lo que ocurre en las escuelas.

Revisando comparativamente estudios locales en décadas anteriores, hemos notado una dificultad persistente en el tiempo para que la retórica de no discriminación y el respeto a la diversidad sean apropiados mediante la operación típica del saber escolar, que es la descontextualización: es decir, la explicitación de los hechos discriminatorios, así como la reivindicación de las diferencias colectivas, en relación con procesos sociales/ históricos/estructurales que se vinculan, pero no se reducen a los hechos entre pares dentro de la escuela. En tal sentido, nuestra discusión de la paradoja disciplinar dialoga con preguntas y desafíos de orden pedagógico.

En este punto, corresponde recordar que la definición estructural de la discriminación pertenece al orden de la experiencia material histórica de los grupos, para nada reductible a fenómenos del orden representacional, cognitivo ni discursivo. Es el carácter específico de las interacciones entre pares y las dinámicas de relación en la escuela lo que nos ha llevado a recortar el plano de las verbalizaciones y la reproducción discursiva de las jerarquías sociales.

Desde esta dimensión de análisis reconstruimos múltiples indicios sobre el peso de las categorizaciones institucionales sobre los y las niñas como alumnos/as, que intervienen en las interpretaciones sobre lo que se vive en el ámbito escolar. La imbricación de los códigos disciplinares a las experiencias discriminatorias despliega un efecto profundamente político y pedagógico: la individualización de lo que experimentan niños y niñas en el ámbito escolar. Tal paradoja de individualización, por otro lado, se despliega en un contexto donde la sanción institucional a la discriminación coexiste con la persistencia de los estigmas y violencias contra las pertenencias colectivas. Y por ello entendemos que las interacciones verbales, donde se reproducen jerarquías entre "lo que se es y lo que no se quiere ser", adquieren su sentido dentro de los procesos de producción y reproducción cultural que atraviesan a la escuela.

En este ámbito, resultan fragmentarias las condiciones simbólicas y discursivas para desestabilizar las jerarquías históricamente instituidas: para poner en duda que ser blanco es mejor que ser negro, defender que los migrantes tienen tantos derechos como los nacionales, o que quienes parecen indios o son hijos de bolivianos son tan argentinos como quienes tienen piel blanca. La persistencia de las jerarquías entre las condiciones étnicas, raciales, nacionales y/o de clase, en el ámbito escolar debe ser pensada en relación con las paradojas en la configuración concreta, situada, del principio de no discriminación y el paradigma de la diversidad en la escuela.

\section{Referencias}

Butler, J. (1998). Soberanía y actos de habla performativos. http://www.accpar.org/numero4/ butler.htm 
Díaz de Rada, Á. (2008). "¿Qué obstáculos encuentra la etnografía cuando se practica en las instituciones escolares?" En M. I. Jociles y A. Franze. ¿Es la escuela el problema? Perspectivas socio-antropológicas de etnografía y educación. Madrid: Editorial Trotta, 24-48.

Fonseca C. y P. Schuch (2009). "Introdução". Políticas de proteção à infância. Um olhar antropológico. Porto Alegre: UFRGS Editora, 9-17.

Grimson, A. (2006). "Nuevas xenofobias, nuevas políticas étnicas en la Argentina”. En A. Grimson y E. Jelin (comps.). Migraciones regionales hacia la Argentina. Diferencia, desigualdad y derechos. Buenos Aires: Prometeo Libros, 69-98.

Guber, R. (2004). "La entrevista antropológica: introducción a la no directividad". En El salvaje metropolitano. Reconstrucción del conocimiento social en el trabajo de campo. Buenos Aires: Paidós, 203-210.

Gutiérrez Rivas, R. (2014). La categoría de discriminación y su relación con el paradigma de los derechos humanos: un apunte crítico. México: Biblioteca Jurídica Virtual-UNAM.

López, N. (2011). “Escuela, identidad y discriminación. Notas introductorias y conclusiones apresuradas". En N. López (coord.). Escuela, identidad y discriminación. Buenos Aires: IIPE-UNESCO, 17-28.

LLobet, V. (2013). “La producción de la categoría niño-sujeto-de derechos y el discurso psi en las políticas sociales en Argentina. Una reflexión sobre el proceso de transición institucional". En: V. LLobet (comp.). Pensar la infancia desde América Latina: un estado de la cuestión. Buenos Aires: CLACSO.

Martínez, L.V. (2017). Niñez, migración y perspectivas de derechos. Una aproximación antropológica en el contexto escolar. Tesis de Doctorado. Facultad de Filosofía y Letras, Universidad de Buenos Aires.

(2018) “La discriminación como categoría social y política en la experiencia escolar de niños migrantes". En: A. Barreiro (comp.). Representaciones sociales, prejuicio y relaciones con los otros. La construcción del conocimiento social y moral. Buenos Aires: Editorial UNIPE.

Neufeld, M. R. y J. A. Thisted (1999). "El crisol de razas hecho trizas: ciudadanía, exclusión y sufrimiento". En: M. R. Neufeld y J. A. Thisted (coords.). De eso no se habla... los usos de la diversidad sociocultural en la escuela. Buenos Aires: Eudeba, 23-56.

Novaro, G. (2002). “Nacionalismo y diversidad cultural en educación. Un análisis antropológico de los contenidos escolares". Tesis de Doctorado en Antropología. Universidad de Buenos Aires. (2011). "Niños migrantes y escuela: ¿identidades y saberes en disputa?". En G. Novaro (coord.). La interculturalidad en debate. Experiencias formativas y procesos de identificación en niños indígenas y migrantes. Buenos Aires: Biblos.

Pacecca, M. I. (2010). “Migrantes de ultramar, migrantes limítrofes. Políticas migratorias y procesos clasificatorios. Argentina, 1945-1970". Revista Temas de Antropología y Migración. Buenos Aires: Universidad de Buenos Aires, 8-34.

Diólo pos 
Pavez, I. (2012). "Inmigración y racismo. Experiencias de la niñez peruana en Santiago de ChiIe". Si somos americanos. Revista de Estudios Transfronterizos, 12(1), 75-99.

Rockwell, E. (2011). La experiencia etnográfica: historia y cultura en los procesos educativos. Buenos Aires: Paidós.

Sánchez Bautista, C. (2013). "Interacciones en la escuela: conflictos, identidades, exclusiones y resistencias". Exclusiones y resistencias de niños inmigrantes en escuelas de Quito. Tesis de Maestría, Ecuador: FLACSO.

Siede, I. (2016). Peripecias de los derechos humanos en el currículo escolar de Argentina. Buenos Aires: Eudeba.

(2013). "La función política de la escuela en busca de un espacio en el currículum" En: G. Schujman e I. Siede (comps.). Ciudadanía para armar. Aportes para la formación ética y política. Buenos Aires: Aique Grupo Editor, 15-38.

Soler Castillo, S. (2013) “Entre negro oscuro y moreno claro. Discursos e identidades étnicas en niños y niñas afrodescendientes en contexto escolar en Bogotá". Educar em Revista, (47), 111-143. Curitiba: Editora UFPR.

\section{Documentos institucionales}

INADI (2011). Somos iguales y diferentes. Guía didáctica para docentes. Primera Edición. http:// www.bnm.me.gov.ar/giga1/documentos/EL005365.pdf

(2013). Racismo y Xenofobia. Hacia una Argentina Intercultural. http://inadi.gob.ar/contenidos-digitales/producto/racismo-y-xenofobia-hacia-una-argentina-intercultural/

(2016a). Racismo y Xenofobia. Hacia una Argentina Intercultural. http://www.inadi.gob.ar/ biblioteca/book/racismo-y-xenofobia/

(2016b). Migrantes y Discriminación. http://www.inadi.gob.ar/biblioteca/book/migrantes-y-discriminacion/

(2016c). Somos iguales y diferentes. Guía para niños y niñas de prevención de prácticas discriminatorias. http://www.inadi.gob.ar/biblioteca/book/somos-iguales-y-diferentes-guiapara-ninas-y-ninos-de-prevencion-de-practicas-discriminatorias/

(2016d). Somos iguales y diferentes. Guía didáctica para docentes. http://www.inadi.gob.ar/ biblioteca/book/somos-iguales-y-diferentes-guia-didactica-para-docentes/ 